\title{
Non-syndromic hypo-hyperdontia-A rare case report and review of literature
}

\author{
Kanika Gupta Verma ${ }^{1}$, Pradhuman Verma ${ }^{2}$, Navneet Singh ${ }^{3}$, Richa Bansal ${ }^{4}$, Rameen Khosa ${ }^{2}$, \\ Gagandeep Kaur Sidhu ${ }^{5}$, Vikas Setia ${ }^{6}$ \\ ${ }^{1}$ Department of Pediatric \& Preventive Dentistry, Surendera Dental College \& RI, Sriganganagar, India \\ ${ }^{2}$ Department of Oral Medicine \& Radiology, Surendera Dental College \& RI, Sriganganagar, India \\ ${ }^{3}$ Department of Oral Pathology \& Microbiology, Maharaja Ganga Singh Dental College \& RI, Sriganganagar, India \\ ${ }^{4}$ Department of Oral Pathology \& Microbiology, Seema Dental College \& RI, Rishikesh, India \\ ${ }^{5}$ Department of Oral Pathology \& Microbiology, Darshan Dental College \& Hospital, Udaipur, India \\ ${ }^{6}$ Department of Pediatric \& Preventive Dentistry, Adesh Dental College \& RI, Bathinda, India \\ Email: drguptakanika@hotmail.com
}

Received 20 September 2013; revised 26 October 2013; accepted 18 November 2013

Copyright (c) 2013 Kanika Gupta Verma et al. This is an open access article distributed under the Creative Commons Attribution License, which permits unrestricted use, distribution, and reproduction in any medium, provided the original work is properly cited.

\begin{abstract}
Abnormalities of tooth number in development of the dentition are quite common; however, concomitant hypo-hyperdontia is a rare mixed numeric anomalous condition, especially when it occurs in the same dental arch and in a non-syndromic situation. The presence of this condition specifically in the mandibular anterior region is reported very infrequently. This case report presents the case of a 9 years old non-syndromic male with missing mandibular central incisors and an erupted mandibular mesiodens along with the review of literature. To ensure optimum function and aesthetics, cosmetic recontouring was performed after oral prophylaxis. This is the ninth case reported in the dental literature till date, with the two anomalies manifesting in the anterior region of the mandible. This article also discusses the review of literature of concomitant hypo-hyperdontia.
\end{abstract}

Keywords: Mesiodens; Hypodontia; Hyperdontia; Mandibular Arch

\section{INTRODUCTION}

Concomitant hypo-hyperdontia (also known as oligopleiodontia) is a rare mixed numeric anomalous condition, where developmental absence of teeth (Hypodontia) and supernumerary teeth (Hyperdontia) co-exist in same individual. The probability of the condition is between 0.0008 and 0.0015 , with most of the cases documented in maxillary arch [1]. The aetiopathogenesis of this simultaneous hyper-hypodontia is obscure [2]. Disturbance in migration, proliferation and differentiation of the neural crest cells and interaction between the epithelial and mesenchymal cells during the initiation stage of tooth development have been suspected as possible causes [3]. Very few cases have been reported with this condition in the English literature till date. Here is the ninth case to be reported with two anomalies manifesting in mandibular anterior region. The rarity of this condition of mixed numerical superiority and inferiority of the human dentition in the mandibular incisor region prompted this report.

\section{MATERIAL AND METHODS}

9-year-old male child and his parents were made aware in advance that the facial photograph will be used for the academic and publication purpose. After the explanation to the patient, written informed consent was taken in local as well as in English language for the same.

Proper institutional protocols regarding ethical issues have been followed. Conflict of interest is disclosed as Nil.

\section{REVIEW OF LITERATURE}

Over the years Mesiodens has been studied extensively. But these have been predominantly in the maxillay arch. Very few cases have been reported in the mandibular arch \& Hypohyperdontia is extremely rare. Here we review this condition (Table 1).

The first case of concomitant hypohyperdontia with missing central incisors and erupted mandibular mesiodens was observed by Low in 1977 [4], followed by Gibson [5], Das et al. [6], Karthik V et al. [7] and Verma KG et al. [8]. Nayak et al. [9] the coexistent hypo-hy- 
Table 1. List of the documented cases in the literature similar to this case.

\begin{tabular}{|c|c|c|c|c|}
\hline Authors & $\begin{array}{l}\text { Age/ } \\
\text { Gender }\end{array}$ & $\begin{array}{c}\text { Hyperdontia } \\
\text { in addition to } \\
\text { mandibular } \\
\text { mesiodens }\end{array}$ & Agenesis & $\begin{array}{c}\text { Any other } \\
\text { significant } \\
\text { findings }\end{array}$ \\
\hline Low (1977) & $7 / \mathrm{M}$ & - & 31,41 & - \\
\hline Gibson (1979) & $6 / F$ & - & 31,41 & - \\
\hline $\begin{array}{c}\text { Das et al. } \\
\text { (2006) }\end{array}$ & $8 / F$ & - & 31,41 & - \\
\hline $\begin{array}{l}\text { Nayak A.G. } \\
\text { et al. (2010) }\end{array}$ & 28/M & - & 32,42 & - \\
\hline $\begin{array}{l}\text { Nuvvula S. } \\
\text { et al. (2010) }\end{array}$ & $15 / M$ & - & 31,41 & $\begin{array}{c}\text { Agenesis of } \\
18,28,48\end{array}$ \\
\hline $\begin{array}{l}\text { Karthik V. } \\
\text { et al. (2011) }\end{array}$ & $9 / \mathrm{F}$ & - & 31,41 & - \\
\hline $\begin{array}{l}\text { Verma K.G. } \\
\text { et al. (2012) }\end{array}$ & 15.6/M & - & 31,41 & - \\
\hline $\begin{array}{l}\text { Marya C.M. } \\
\text { et al. (2012) }\end{array}$ & 20/M & - & 31,41 & $\begin{array}{c}\text { Agenesis of } \\
18,28,48\end{array}$ \\
\hline $\begin{array}{l}\text { Verma K.G. } \\
\text { et al. (2013) } \\
\text { Present case }\end{array}$ & 9/M & - & 31,41 & $\begin{array}{c}\text { Agenesis of } \\
18,28,38,48\end{array}$ \\
\hline
\end{tabular}

perdontia with missing lateral incisors and erupted mandibular mesiodens. Nuvvula S et al. [10] and Marya CM et al. [1] reported similar cases of hypohyperdontia along with agenesis of 18, 28 and 48. Other than the eight cases described above, our is reported to be the ninth case with coexistent hypohyperdontia in mandibular anterior region along with congenitally missing $18,28,38$ and 48 to the best of our knowledge.

\section{CASE REPORT}

\subsection{Case History}

A 9-year-old male reported to the department of pedodontics and preventive dentistry with a chief complaint of blackish stains in his maxillary and mandibular teeth for the previous 3 to 4 months. A history of presenting illness revealed that there were moderate amounts of blackish stains in maxillary and mandibular teeth, as the patient was not maintaining his oral hygiene properly. He brushes his teeth once a week using a horizontal brushing technique. There was no history of trauma, infection or metabolic disorders in his childhood. This was the patient's first dental visit with no prior experience of having undergone any dental procedure. Medical history and family history was non-contributory. The patient was the only child, born to parents of a non-consangious marriage. On complete physical examination, no syndromic features were noticed. The boy was of normal build and height and well oriented to time and place with a normal I.Q. All the vital signs were within normal limits.
Haematological and serological values were within normal limits. Ultrasound examination of the abdomen did not reveal any abnormality of the kidney, liver, intestine, genitourinary tract etc.

\subsection{Intra-Oral Examination}

Soft tissue examination showed pinkish red, firm, resilient gingivae with presence of stippling. Hard tissue examination revealed the absence of the mandibular central incisors bilaterally and presence of a supplemental supernumerary tooth in the midline (Figure 1).

The morphology of the clinical crowns of the two incisors present and the absence of spacing between the incisors and canines indicated the congenitally missing central incisors.

\subsection{Radiographs}

An intra-oral periapical radiograph of the lower anterior region showed the absence of 31 and 41 . There was a supplemental mesiodens with complete root formation, with no evidence of any pathologic periapical changes (Figure 2).

The close approximation of the roots of the mesiodens and incisors, and no spacing between the incisors and canines, highlighted the absence of the central incisors. An orthopantomogram confirmed the absence of both the mandibular central incisors along with the presence of a mesiodens in the midline. Other findings in the orthopantomogram were within normal limits considering the age of child (Figure 3).

\subsection{Diagnosis}

Based upon the history and clinical examination, a provisional diagnosis of mandibular hypo- and hyperdontia was made and the differential diagnosis of orodigitofacial dysostosis, Hallerman Streiff and Cleidocranial dys-

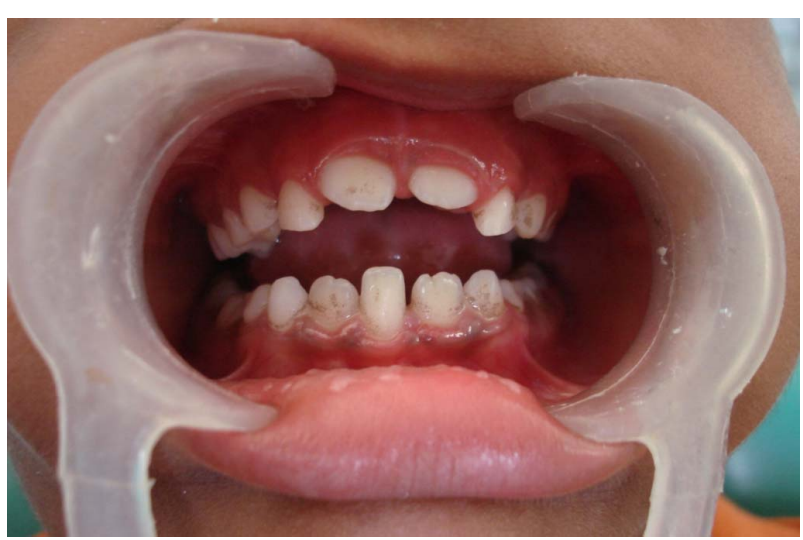

Figure 1. Intra-oral photograph showing the absence of mandibular central incisors bilaterally and presence of a conical shaped mesiodens. 


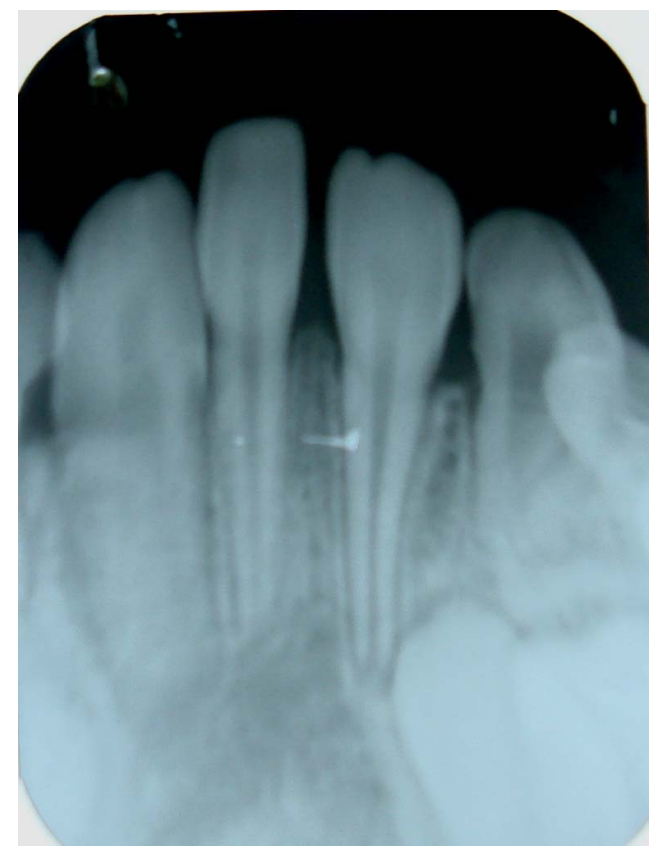

Figure 2. Intraoral periapical radiograph showing the conical shaped mesiodens with complete root formation without any evidence of pathologic periapical changes.

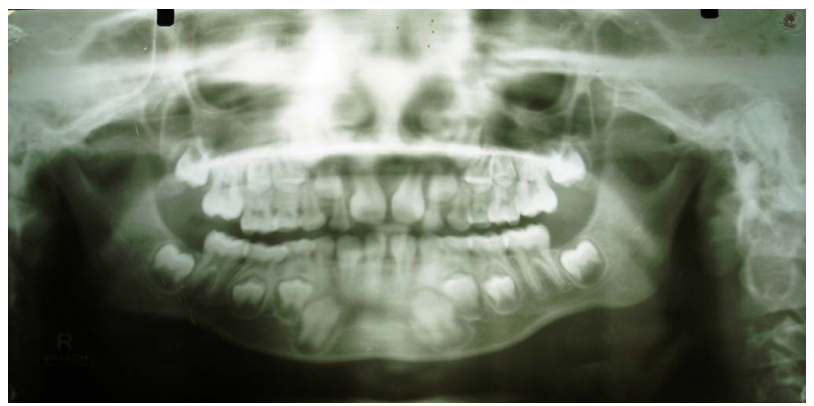

Figure 3. Orthopantomogram showing the mesiodens in approximation with mandibular lateral incisors and no other significant findings.

plasia syndrome were considered. Based upon the history, clinical features and radiological investigations the final diagnosis of mandibular anterior hypohyperdontia was made.

\subsection{Treatment}

A full mouth prophylaxis with scaling and removal of calculus and stains was performed. The treatment of choice here would have been to restore the mesiodens to the appearance of a normal incisor. Although this would have been a centrally placed "incisor" the alignment in the arch would not have appeared abnormal. This approach to treatment was fully explained to the patient's parents and the cosmetic recontouring of mesiodens was done (Figure 4). Oral hygiene instructions were given.

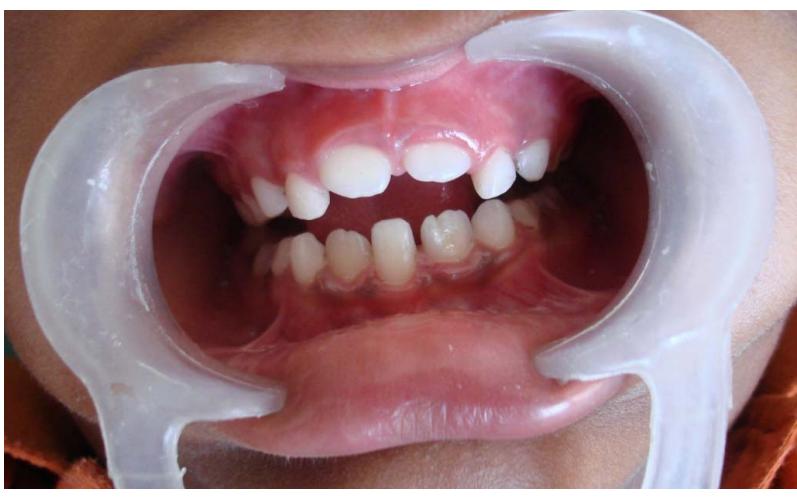

Figure 4. Intra-oral photograph showing complete oral prophylaxis and cosmetic recontouring of mesiodens.

\subsection{Follow-Up}

The patient was advised to give follow-up every six months to assess his erupting dentition and oral health status.

\section{DISCUSSION}

Agenesis of teeth is the most common developmental craniofacial anomaly in humans. Mutations in Genes PAX9, MSX1 and AXIN2 have been implicated as probable cause for the agenesis in non-syndromic hypodontia [11]. The usual mode of inheritance of hypodontia is autosomal dominant, but occasionally autosomal recessive and X-linked and polygenic/multifactorial models of inheritance have also been reported [4]. Many terminologies have been used in the past to describe this condition, such as "concomitant hypodontia and hyperdontia", and oligopleiodontia [9]; however, now the preferred term is "hypo-hyperdontia" as suggested by Gibson [5] and reported by Anthonappa et al., [12]. Hypohyperdontia is rare in isolation and has been associated with over 50 syndromes, notably orodigitofacial dysostosis, Hallerman Streiff, Cleidocranial dysplasia syndrome, Ellis van Creveld, Downs syndrome, cleft lip and palate, and many others [12-14]. Agenesis of teeth is more common in permanent dentition and is also more prevalent in females (1.37:1; F:M) as reported by Polder et al., in 2004 [15]. The case reported is recorded in mixed dentition stage in a male child. Studies have demonstrated that hypodontia tends to be more common in mandible than maxilla. In Asian populations, the mandibular incisors are the most commonly missing teeth, followed by the mandibular second premolars [16]. There is a tendency for dental agenesis to occur more unilaterally than bilaterally. In the case reported herein there were missing mandibular central incisors along with agenesis of four third molars; however the supernumerary tooth was a mandibular mesiodens, a rare occurrence by itself. The reported prevalence for hypo- 
hyperdontia [12] from various studies has been calculated to range from $0.002 \%$ to $3.1 \%$. Hypo-hyperdontia does not usually manifest in the same arch and very rarely in the same area of an arch [6,12]. Patients with hypo-hyperdontia usually do not present any symptoms and are usually detected during examination for other causes or on radiographic examination of the jaws [10, 17,18]. The current case was only recognised when the patient came for oral prophylaxis. When any numeric anomaly of the dentition is noted, a thorough clinical intra-oral examination is warranted, combined with a judicious use of radiographs. Panoramic radiographs are the best screening modality available by virtue of demonstrating the entire teeth-bearing segment of the jaws and supporting structures in a single image [19]. Additional information about the root morphology and root development can be obtained using periapical views. In the present case, the age of the patient (9 years) precluded any possibility of late development of at least the mandibular central incisors, as some radiographic evidence would have been noted. Having stated this it will still have to be emphasised that in most cases supernumerary as well as unerupted teeth go undetected and clinicians have to make the effort to determine these conditions by a thorough clinical as well as radiographic examination. Such rare situations can at times significantly alter the treatment plan and enough latitude should be considered in managing such clinical circumstances.

\section{CONCLUSION}

Due to the rarity of combined hypodontia of the mandibular incisors and the presence of the mandibular mesiodens, treatment of affected children is generally undertaken. Multidisciplinary treatment planning, which takes account of established and emerging techniques, needs to be practiced [8]. Different treatment options that take account of growth and development of the dentition and of the compliance of child can lead to a treatment plan that can produce desirable interim results, which do not compromise any future treatment. Careful treatment planning is important, because there is a need to deal with not only the immediate but also the long-term adverse implications.

\section{REFERENCES}

[1] Marya, C.M., Sharma, G., Parashar, V.P., Dahiya, V. and Gupta, A. (2012) Mandibular midline supernumerary tooth associated with agenesis of permanent central incisors: A diagnostic conundrum. Stomatologija, Baltic Dental and Maxillofacial Journal, 14, 65-68.

[2] Ratna, R. (1988) Numeric anomalies of teeth in concomitant hypodontia and hyperdontia. Journal of Craniofacial Genetics and Developmental Biology, 8, 245-251.

[3] Sharma, A. (2001) Mandibular midline supernumerary tooth: A case report. Journal of Indian Society of Pedodontics and Preventive Dentistry, 19, 143-144.

[4] Low, T. (1977) Hypodontia and supernumerary tooth: Report of a case and its management. British Journal of Orthodontics, 4, 187-190.

[5] Gibson, A.C.L. (1979) Concomittant hypo-hyperdontia. British Journal of Orthodontics, 6, 101-105.

[6] Das, G., Sarkar, S., Bhattacharya, B. and Saha, N. (2006) Coexistent partial anodontia and supernumerary tooth in the mandibular arch: a rare case. Journal of Indian Society of Pedodontics and Preventive Dentistry, 24, 33-34.

[7] Karthik, V., Muralikrishnan, B. and Anantharaj, A. (2011) Mandibular mesiodens with agenesis of central incisors (Hypohyperdontia): A case report \& review. International Journal of Contemporary Dentistry, 2, 26-30.

[8] Verma, K.G., Verma, P. and Rishi, S. (2012) Case report: A rare occurrence of non-syndromic hypo-hyperdontia in the mandibular anterior region. European Archives of Paediatric Dentistry, 13, 46-48. http://dx.doi.org/10.1007/BF03262841

[9] Nayak, A.G., Chhaparwal, Y., Pai, K.M. and Lele, A.S. (2010) Non-syndromic hypo-hyperdontia of the permanent dentition with involvement of the mandibular anterior region: A rare occurrence. Revista de Clínica e Pesquisa Odontológica, 6, 281-284.

[10] Nuvvula, S., Kiranmayi, M., Shilpa, G. and Nirmala, S. (2010) Hypohyperdontia: Agenesis of three third molars and mandibular centrals associated with midline supernumerary tooth in mandible. Contemporary Clinical Dentistry, 1, 136-141. http://dx.doi.org/10.4103/0976-237X.72775

[11] Matalova, E., Fleischmannova, J., Sharpe, P.T. and Tucker, A.S. (2008) Tooth agenesis: From molecular genetics to molecular genetics. Journal of Dental Research, 87, 617-623. http://dx.doi.org/10.1177/154405910808700715

[12] Anthonappa, R.P., Lee, C.K., Yiu, C.K.Y. and King, N.M. (2008) Hypo-hyperdontia: Literature review and report of seven cases. Oral Surgery, Oral Medicine, Oral Pathology, Oral Radiology, 106, 24-30. http://dx.doi.org/10.1016/j.tripleo.2008.07.012

[13] Zhu, J.F., Crevoisier, R. and Henry, R.J. (1996) Congenitally missing permanent lateral incisors in conjunction with a supernumerary tooth: Case report. Pediatric Dentistry, 18, 64-66.

[14] Varela, M., Arrieta, P. and Ventureira, C. (2009) Nonsyndromic concomitant hypodontia and supernumerary teeth in an orthodontic population. European Journal of Orthodontics, 31, 632-637. http://dx.doi.org/10.1093/ejo/cjp046

[15] Polder, B.J., Van’t Hof, M.A., Van der Linden, V.P. and Kuijpers-Jagtman, A.M. (2004) A meta-analysis of the prevalence of dental agenesis of permanent teeth. Community Dentistry and Oral Epidemiology, 32, 217-226. http://dx.doi.org/10.1111/j.1600-0528.2004.00158.x

[16] Nagaveni, N.B. and Umashankara, K.V. (2009) Congenital bilateral agenesis of permanent mandibular incisors: Case reports and literature review. Archives of Orofacial Sciences, 4, 41-46. 
[17] Sharma, A. (2008) A rare case of concomitant hypo-hyperdontia in identical twins. Journal of Indian Society of Pedodontics and Preventive Dentistry, 26, S79-S81.

[18] Raghavan, V.H. (2009) Mandibular mesiodens with agenesis of central incisors-A rare association. Nigerian
Dental Journal, 17, 27-28.

[19] Marilia, A. (2005) Lower mesiodens: Report of an unusual case. Journal of Clinical Pediatric Dentistry, 29, 353-356. 